\title{
Ensañamiento y reparación del daño: análisis de una reciente sentencia de interés del Tribunal Supremo
}

JE. Vázquez López

Abogado. Sevilla

Correspondencia:

J. Enrique Vázquez López

E-mail:

jevazquez@orange.es
"El sabio no se sienta para lamentarse, sino que se pone alegremente a su tarea de reparar el daño hecho."

William Shakespeare
El daño y su reparación son acciones distintas, y por definición no pueden coincidir en el tiempo. A saber, primero se produce el daño, y con posterioridad es cuando la reparación es posible. De este modo, y quizá por una influencia de tendencia ética, tanto las personas individuales como el Estado en cuanto ente que gobierna, están siempre dispuestos a otorgar cierta dosis de perdón si la acción ilícita es reconocida por su autor y si este procede a realizar, al menos, un intento de reparación. Aquí viene justificada la existencia de las circunstancias que atenúan la conducta penal si el autor de esta, como digo, procede a reparar parte del daño causado.

Sin embargo, este intento de reparación ha de tener una serie de requisitos, que han venido siendo configurados por nuestra jurisprudencia a lo largo de los años. Y el primero de estos requisitos es, lógicamente, que ese intento sea sido real, esto es, sincero y que no encubra otro tipo de motivación, como por ejemplo la de beneficiarse de una reducción de la pena sin que el autor haya en realidad reparado nada.

Este supuesto es el que analizaremos en la reciente Sentencia del Tribunal Supremo de fecha 7 de Octubre de 2014, dándose la circunstancia de que a la vez tendremos ocasión de dilucidar la pregunta que mucha gente de la calle se realiza cuando este tipo de sucesos tiene acceso al gran público: ¿es compatible entonces el ensañamiento con la víctima con la apreciación posterior de una atenuante de reparación del daño por parte del tribunal sentenciador? Ahora lo veremos.

No obstante, con carácter previo, recordemos los preceptos que contemplan ambas circunstancias modificadoras de la responsabilidad criminal, la una como agravante constitutiva del asesinato y excluyente del homicidio -el ensañamiento- y la otra como atenuante de la conducta criminal.

El artículo 139 Código Penal dice: "Será castigado con la pena de prisión de quince a veinte años, como reo de asesinato, el que matare a otro concurriendo alguna de las circunstancias siguientes:

- 1. ${ }^{a}$ Con alevosía.

- 2. a Por precio, recompensa o promesa.

- 3. a Con ensañamiento, aumentando deliberada e inhumanamente el dolor del ofendido".

Aquí tenemos que cualquier muerte en la que concurra ensañamiento sería asesinato, por tanto, y no homicidio.

Y por otro lado tenemos lo previsto en el artículo 21.5 del Código Penal, que contempla la atenuante de reparación del daño en los siguientes términos: "La de haber procedido el culpable a reparar el daño ocasionado a la víctima, o disminuir sus efectos, en 
cualquier momento del procedimiento y con anterioridad a la celebración del acto del juicio oral".

Así, la atenuante debería apreciarse si el culpable repara el daño causado o disminuye sus efectos.

Y una vez sentadas las bases del debate, pasemos al análisis del caso.

\section{Los hechos y la primera sentencia}

Se recogen literalmente de la Sentencia de fecha 17 de abril de 2013 emitida por la Audiencia Provincial de Granada, y son los siguientes:

"Son hechos probados, conforme al veredicto emitido por el Jurado, y así expresamente se declaran, los siguientes:

El acusado José, con D.N.I. NUM000, nacido en San Javier (Murcia) el NUMO01 de 1990, sin antecedentes penales, privado de libertad por esta causa desde el día 20 de julio de 2011, y Sagrario (de 18 años de edad a la fecha de los hechos) venían manteniendo una relación sentimental de noviazgo desde aproximadamente comienzos del año 2010, habiendo incluso llegado a convivir durante algunos meses.

El día 19 de julio de 2011, en hora no determinada pero comprendida entre las 20:00 y las 21:30 horas, a bordo del vehículo marca Peugeot 206, modelo XT 90, de color gris, con matrícula TV-....-UV, el citado acusado y Sagrario, accedieron a través de un camino de tierra que parte desde la carretera A-385 (Otura-La Malahá), a un lugar lejano a cualquier núcleo urbano o vivienda habitable y no visible desde la citada carretera. Una vez en dicho lugar, y dentro del vehículo, iniciaron una discusión por motivos no concretados, en el curso de la cual el acusado comenzó a agredir a Sagrario, intentando ésta defenderse arañando y mordiendo a José en los brazos y muñecas. Sagrario logró salir del vehículo, si bien fue perseguida y alcanzada por el acusado, quien con el propósito de acabar con su vida, aprovechando sus conocimientos en la práctica de técnicas de combate corporal como el full contact y el kick boxing, y con el propósito de aumentar deliberadamente su sufrimiento y dolor, continuó su agresión física sobre ella y dirigió sus golpes hacia Sagrario, especialmente hacia la cabeza y la cara, de cejas hasta el cuello. Completamente aturdida y sin capacidad de reacción por los golpes recibidos, el acusado a Sagrario asestó un fuerte golpe en el cuello que le ocasionó un reflejo vagal y una "he- morragia aguada" tanto en el encéfalo como en el ECM (yugular, carótida y vago), con parada cardíaca y fallecimiento de Sagrario.

A continuación, el acusado arrastró a Sagrario y la subió al asiento trasero del vehículo, en el que la llevó al Hospital Clínico San Cecilio donde ingresó a las 22:44 ya fallecida y con signos de frialdad postmórtem. Ello no obstante, y dada la juventud de la víctima, los facultativos de Urgencias aplicaron a Sagrario el protocolo de reanimación cardiorrespiratoria sin resultado positivo.

La autopsia de Sagrario constató, además del síndrome de insuficiencia cardiorrespiratoria aguda, asociado a un trauma vagal por el golpe propinado en el cuello, una multiplicidad de lesiones en la cara, tórax, parte anterior y mamas, en la espalda, en los miembros superiores e inferiores, así como en la cara, cuello y cráneo, pudiendo afirmarse que todas las erosiones, heridas lineales y erosiones contusas (en número de 198)-individualmente consideradas- per se no fueron causa de fallecimiento, siendo la herida interna que Sagrario tenía en el cuello, dado el reflejo vagal de la misma, la que causó una inmediata parada cardíaca.

Sagrario era soltera y convivía con sus padres y con su hermano Alfredo - menor de casi 11 años de edad-, así como con otros dos menores de edad Celestino y Juliana, de 5 y 6 años de edad respectivamente, acogidos en régimen de acogimiento familiar permanente".

A estos hechos procedió en su momento una condena por parte de la Audiencia en los siguientes términos:

"Debo CONDENAR y CONDENO a José, como autor penalmente responsable de un delito de asesinato previsto y penado en el art. 139, circunstancias $1^{a}$ y $3^{a}$, del Código Penal (circunstancias de alevosía y ensañamiento) con la concurrencia de las circunstancias modificativas agravante genérica de parentesco del art. 23 del Código Penal, a la pena de veintitrés años de prisión, con accesoria de inhabilitación absoluta durante el periodo de condena, prohibición de aproximación a los padres y hermanos de Sagrario, a su domicilio, lugar de trabajo o cualquier otro donde pudieran hallarse, y de comunicación con los mismos por cualquier medio, incluidos los telemáticos, a una distancia no inferior a 300 metros durante un periodo de treinta años, al pago de las costas causadas, incluidas las de la acusación particular, y a que indemnice a los padres de Sagrario, D. Eugenio y $D^{a}$. Leticia, con la cantidad, a cada uno, de noventa y nueve mil euros (99.000€), a su hermano menor Alfredo con 
la cantidad de dieciocho mil euros (18.000€) y a los menores en acogimiento familiar permanente Celestino y Sagrario (sic) a cada uno, igualmente con la cantidad de dieciocho mil euros (18.000€), por el daño moral causado".

\section{Sentencia de Segunda Instancia}

Ante dicho fallo se alzó la representación procesal del condenado mediante recurso de apelación, dictándose tras la tramitación legal pertinente una nueva sentencia con el siguiente fallo:

"Que estimando parcialmente el recurso interpuesto por la defensa de José contra la sentencia dictada por el IImo. Sr. Magistrado Presidente del Tribunal del Jurado, en el ámbito de la Audiencia Provincial de Granada, Sección Segunda, hemos de revocar dicha sentencia parcialmente en el sentido de condenar al acusado como autor de un delito de asesinato con alevosía y ensañamiento, con la concurrencia de la circunstancia agravante de parentesco y la atenuante de reparación del daño, a la pena de veinte años de prisión, confirmando el resto de pronunciamientos de la sentencia apelada, y sin condena al pago de las costas causadas en esta alzada".

Así, en apelación se estima que la conducta del procesado es merecedora de la aplicación de la atenuante de reparación del daño, y en consecuencia se reduce la pena a imponer. ¿En qué se basó el Tribunal Superior de Justicia de Andalucía para apreciar dicha atenuante? Pues fundamentalmente en el hecho de que el culpable llevó, con posterioridad a la brutal agresión, a su víctima al hospital. Simple y llanamente.

Contra dicha sentencia se interpuso recurso de casación por parte de la acusación particular, y por la Junta de Andalucía, fundamentalmente por indebida aplicación de la atenuante de reparación del daño.

\section{La sentencia del Tribunal Supremo}

Su ponente es D. Luciano Varela Castro. La primera apreciación que realiza la sentencia es un reproche a la revocación de apelación por la que se estimaba la atenuante de reparación del daño. Así, se entiende que esta revocación toca un elemento esencial del relato que sobre los hechos realiza el jurado, y este elemento pasa por la afirmación de que el acusado no quería asistir a la víctima. Frente a esta aseveración realizada por el jurado popular, la Audiencia afirma que el acusado actuó, al llevar a Doña Sagrario al hospital, con la sincera intención de evitar su muerte. ¿Cómo pueden valer ambas afirmaciones? Esto es lo que se plantea el Tribunal Supremo, y lo que rotundamente niega, es decir, la posibilidad de respetar los hechos que se declaran probados, por un lado, mientras por otro se aprecia una atenuante que viene a significar lo contrario.

Entrando ya de lleno en el análisis del recurso, la sentencia no tiene dudas a la hora de calificar la indebida apreciación de la atenuante con estos términos:

"Y además porque tampoco el sentido común contradice la valoración de los medios probatorios llevada a cabo por el Jurado. La brutalidad que condujo al triste fallecimiento de la víctima se compadece mal con ese propósito de remedo del mal causado que la sentencia ante nosotros recurrida se cree. Las condiciones en que el cadáver llega al centro hospitalario predican una antigüedad en el fatal desenlace, que predica un muy significativo retraso en la supuesta voluntad reparadora, sugerente de propósitos ajenos a la recuperación de una vida que el autor había extinguido tiempo atrás.

Como el Tribunal Superior admite paladinamente en su recurrida sentencia, la víctima se encontraba en un estado muy irreversible, haciendo de todo auxilio una maniobra, desde el principio, ineficaz".

De esta manera, la sentencia ya de entrada anticipa que va a estimar el recurso al entender que la labor interpretativa realizada por el Tribunal Superior se ha excedido en cuanto que no ha modificado el relato fáctico del jurado, aun llegando a conclusión distinta.

No obstante, continúa la motivación en cuanto a la atenuante en sí desglosando y recordando los elementos básicos que configuran su apreciación, haciendo hincapié en que la reparación debe ser suficientemente significativa y relevante, pues no procede conceder efecto atenuante a acciones ficticias “...que únicamente pretenden buscar la aminoración de la respuesta punitiva sin contribuir de modo eficiente y significativo a la efectiva reparación del daño ocasionado".

Finalmente, la sentencia, con una rotundidad que pocas veces hemos visto en los textos del Supremo, estima el recurso y finaliza con las siguientes afirmaciones que recogemos de modo literal:

"Aun admitiendo la inadmisible hipótesis de un actuar bienintencionado en el autor del brutal homicidio, es lo cierto que objetivamente su com- 
portamiento resultó absolutamente irrelevante. Y la tardanza en el traslado de la víctima aleja al autor incluso de la hipótesis del actus contrarius antes objeto de mención. Así, ni se lograron los fines de política criminal de la atenuante, ni cabe predicar del autor un oportuno avance rehabilitador que justifique premio alguno en la sanción que merece".

\section{El fallo de la sentencia del Tribunal Supremo}

La estimación del recurso conlleva la anulación de la sentencia recurrida, dictándose a continuación otra nueva que no estima la apreciación de la atenuante de reparación del daño.

\section{Conclusiones}

En el caso analizado resulta evidente que, constatándose que la víctima sufrió un total de 198 heridas, el ensañamiento no puede discutirse. Es más, el procesado hizo gala de sus conocimientos en artes marciales para proporcionar más dolor del que realmente era necesario para causar la muerte. Por ello, la primera parte de la conducta del culpable se realizó con claro ensañamiento. Ahora bien, esto en modo alguno resulta incompatible con la reparación del daño, como de hecho ya estimó el Tribunal Superior de Justicia, aunque erróneamente en este caso, ya que el agresor, por mor de un cambio de actitud o un postrero arrepentimiento, puede realizar todo lo necesario para reparar el daño causado, y en el caso sería el hecho de acudir junto con la víctima al hospital para que el fallecimiento finalmente no se produjera. Sin embargo, al caso no cabe apreciarle la atenuante por una serie de razones bien sopesadas por el Alto Tribunal: la primera de ellas por el hecho indiscutible de que Sagrario llegó cadáver al centro hospitalario, y en segundo lugar porque del examen de los hechos puede inferirse sin temor a engaños un retraso en el traslado que casa mal con la atenuante pretendida, por todo lo cual entiendo que la sentencia anula la anterior con buen criterio.

Y como ya dijo el maestro Shakespeare, la tardanza en reparar equivale a no reparar nada en absoluto, y al caso me remito. 